$\mathrm{Oz}$

Volume 25

Article 23

$1-1-2003$

\title{
Lexton MacCarthy Residence
}

Follow this and additional works at: https://newprairiepress.org/oz

Part of the Architecture Commons

(c) (1) $9 \Theta$

This work is licensed under a Creative Commons Attribution-Noncommercial-No Derivative Works 4.0 License.

\section{Recommended Citation}

(2003) "Lexton MacCarthy Residence," Oz: Vol. 25. https://doi.org/10.4148/2378-5853.1400

This Article is brought to you for free and open access by New Prairie Press. It has been accepted for inclusion in Oz by an authorized administrator of New Prairie Press. For more information, please contact cads@k-state.edu. 


\title{
Lexton MacCarthy Residence
}

\author{
Lorcan O'Herlihy Architects
}

Isolating the hillside house as a building type is very important for architectural discourse. Sloping sites offered California modernists, Wright, Schindler, Neutra, Lautner, and others, the opportunity to invent new forms, transforming the house. Continuing in this tradition the Lexton/MacCarthy site offered wonderful west facing views of Los Angeles and suggested a formal strategy of an abstract geometrical form conceived as a play of positive and negative volumes.

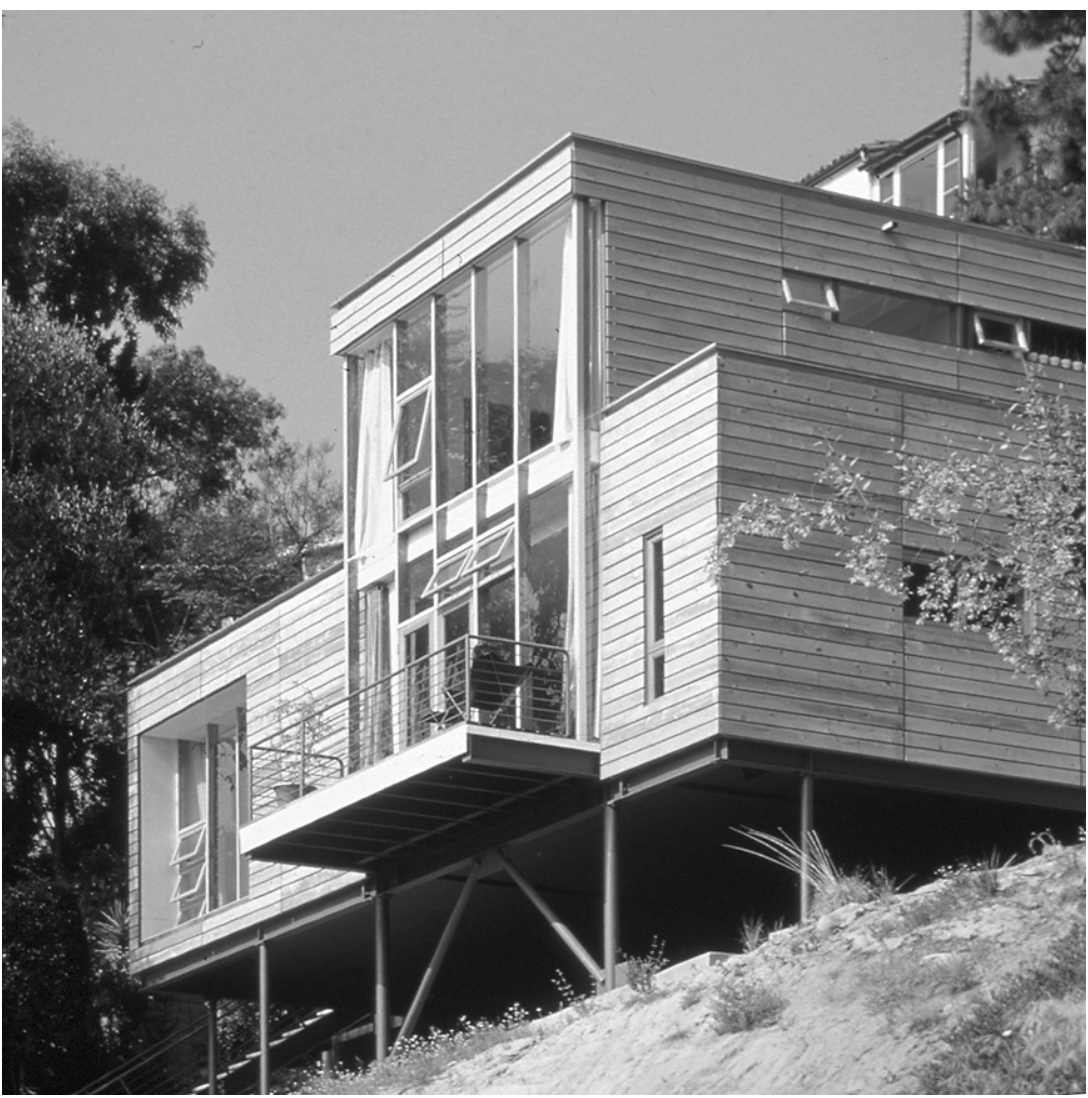

in Silver Lake. The deep vertical section of the site did not lend itself to an easy solution. The siting of the house carport, and stair was conceived as a "straight dislocation." The carport "breaks away" from the house with its path traced by a connecting stairway. Retaining walls, excavation, and site grading are typically a major portion of the construction cost for hillside houses. The building pad elevation and siting were considered to minimize the heights of retaining walls and amount of grading.

The program was for a two thousand square foot house with a carport. Given the limited square footage of the house, the primary floor is conceived as a free plan, which allows for programmatic flexibility. The second story houses the master bedroom suite. The section of the second floor traces an area on the first floor that houses the kitchen, stair, bathroom and closet. The build-
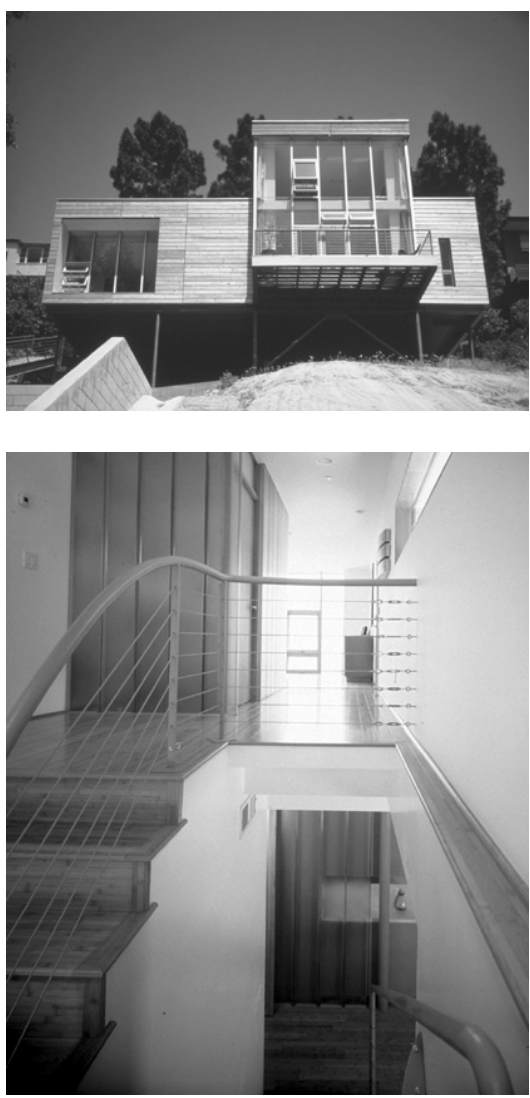

ing fenestration on the west wall at the living room are receding and the fenestration at the core of the house reinforces the vertical line through the glue-laminated columns. The house is wrapped in 1 inch by 6 inch Douglas fir horizontal siding which floats away from the structure with 2 inch by 2 inch vertical spacers. The second floor siding is stained blue.

The internal plan and distribution of program is suggested in the treat
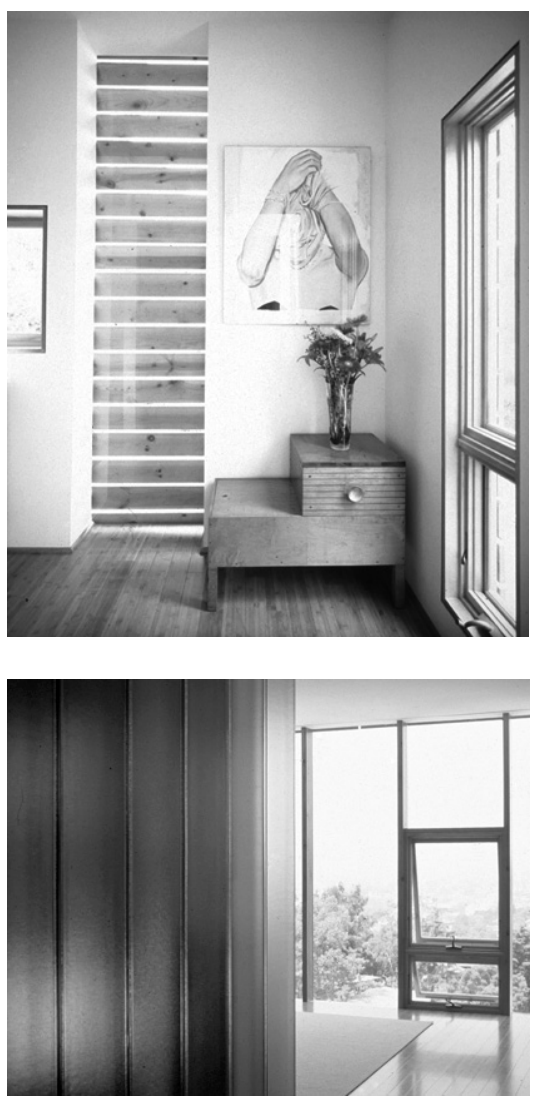
ment of the exterior skin. The idea of the house is to establish a horizontal layer on the primary floor and vertical volume on the second floor.

A new vocabulary for wood structures was proposed. The formal simplicity allows for a greater focus on materials, proportions, and details. The abstract geometrical forms stripped of superfluous detailing reinforces the modernist reticence, but is mediated through the use of wood surface
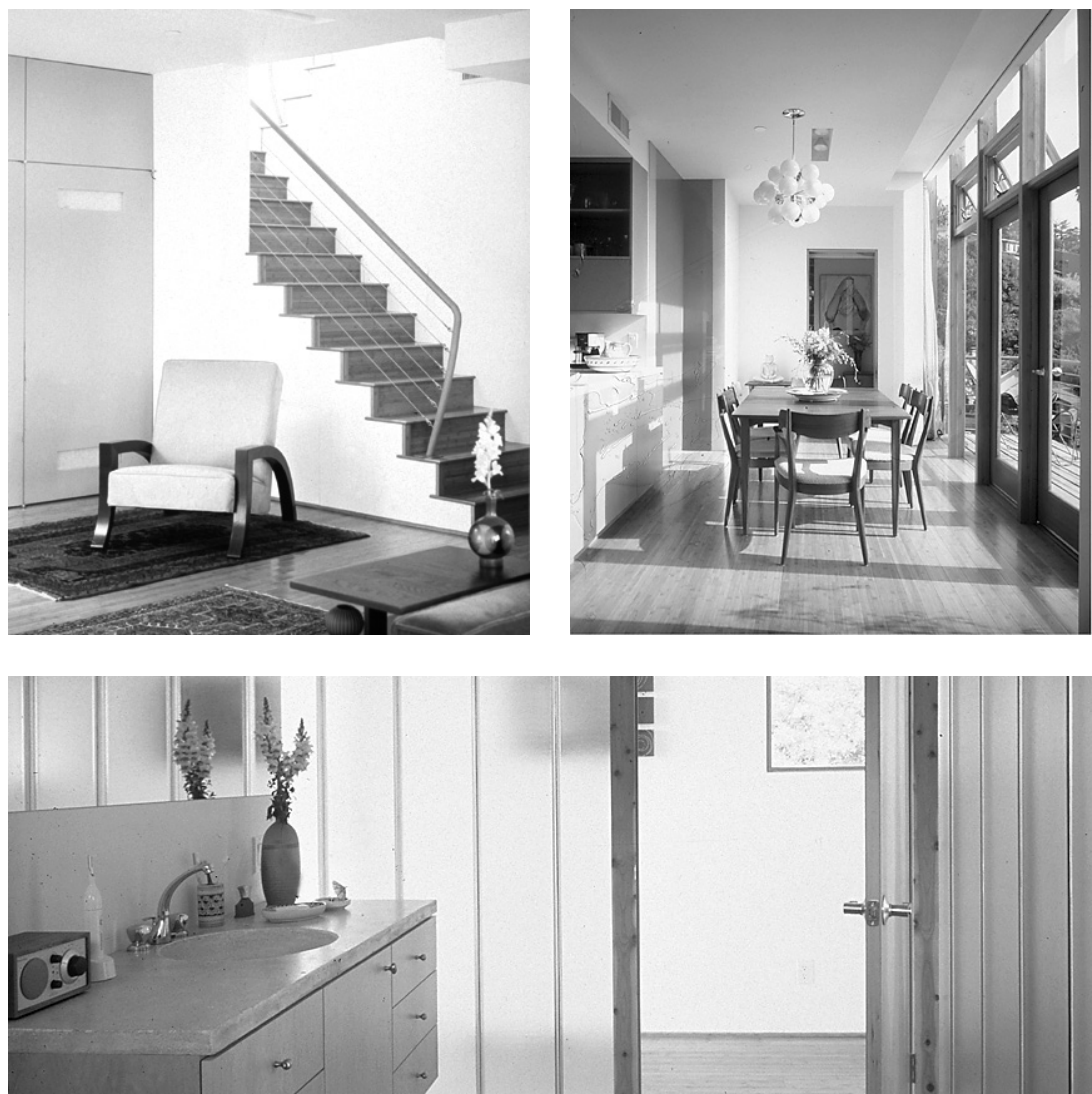
